\title{
Hubungan Keaktifan \\ Ekstrakurikuler Pendidikan \\ Keperamukaan Dengan Sikap \\ Disiplin Siswa Kelas Tinggi SDN 36 \\ Kota Bengkulu
}

\section{Rika Marlina}

Universitas Bengkulu

rikamarlina178@gmail.com

\section{Lukman}

Universitas Bengkulu

Toplukman23@gmail.com

\section{Wurjinem}

Universitas Bengkulu

Wurdjinem.pgsd@yahoo.com

\begin{abstract}
This study aims to determine the relationship between the activeness of students following extracurricular scouting education with student discipline attitudes. This research is quantitative research. The research method used is the correlation with the type of product moment design. The population in this study were all high-class students who took extracurricular scouting education. Sampling using random sampling but the sample in this study the entire population because it is less than 100 then the entire population is sampled with a total of 57. The research instrument used was a questionnaire sheet. Prerequisite test data analysis using tests of normality, homogeneity and hypothesis. This technique is used to determine the significant relationship between independent and dependent variables by comparing $r_{-} c a l c u l a t i o n s$ and $r_{-}$tabels with a significant level of $5 \%$. Based on the results of data analysis, the value of $r_{-}$calculations $=0.66>\quad r_{-}$tabels $=0.266$, which means that there is a significant relationship between activeness in scouting extracurricular education and disciplinary attitude. Furthermore, the significance test results obtained t_calculations $=6.8 \geq t$ _tabels $=1.67303$ means that there is a significant relationship between variables for the entire population with a contribution of $43.56 \%$ between the activities of joining extracurricular scouting education with student discipline attitude. It was concluded that Ha was accepted where there was a relationship between the activities of joining the scouting extracurricular education with the discipline attitude of high class students at 36 Primary Schools in Bengkulu City.
\end{abstract}

Keywords: activity, extracurricular, scouting education, discipline 


\section{Pendahuluan}

Pada saat ini karakter manusia sedang mengalami kemerosotan. Salah satu contohnya sekarang banyak yang tidak tepat waktu, datang sering terlambat. Pendidikan karakter memiliki 18 nilai yang dikembangkan salah satunya sikap yang mengalami kemerosotan adalah sikap disiplin . Disiplin merupakan sikap yang perlu dimiliki peserta didik karena dengan memiliki sifat disiplin peserta didik memiliki perilaku yang tertib dan patuh pada berbagai ketentuan maupun peraturan. Berdasarkan analisa Departemen Pendidikan Nasional dalam Aini ( 2015 ) menyatakan bahwa "Tingkat disiplin siswa sekarang ini sangat rendah baik dalam menaati peraturan, tata tertib sekolah maupun dalam mengikuti pelajaran, sehingga mengakibatkan lingkungan sekolah kurang kondusif." Sedangkan menurut Fathurrohman (2013:79) disiplin merupakan suatu perilaku ataupun tindakan unttuk menunjukkan perilaku patuh dan tertib pada berbagai peraturan dan ketentuan yang berlaku . Sikap disiplin siswa ini sangat mempengaruhi hasil belajar dari siswa semakin tinggi tingkat disiplin maka hasil belajar juga semakin baik. Tingkat disiplin siswa yang memiliki tingkat kedisiplinan yang tinggi selalu memperoleh nilai yang sangat baik. Siswa yang tingkat kedisipilinannya sedang ada yang memperoleh nilai yang sangat baik dan ada pula yang memperoleh nilai yang baik. Sedangkan siswa yang tingkat kedisiplinannya rendah ada yang sering mendapat nilai yang baik dan ada yang memperoleh nilai yang rendah dalam jurnal (Elly, 2016 : 52).

Hal ini terlihat masih banyak siswa yang tidak mengerjakan tugas dan tidak masuk ke dalam kelas tepat waktu. Oleh karena itu disimpulkan masih rendahnya sikap disiplin yang tertanam dalam diri siswa yang dapat dilihat dari pelanggaran yang terjadi. Upaya yang dapat mengatasi peningkatan sikap disiplin adalah dengan pendidikan. Pendidikan merupakan cara penting untuk mengembangkan manusia yang bermutu dan berkualitas. Melalui pendidikan dapat menjadikan seseorang lebih bertaqwa kepada Tuhan Yang Maha Esa, yang memiliki kepribadian, pengetahuan dan keterampilan yang berguna bagi diri sendiri dan lingkungan. Sesuai dengan bunyi Undang-Undang No. 20 tahun 2003 tentang sistem pendidikan yang menyatakan bahwa pendidikan adalah usaha sadar dan terencana untuk mewujudkan suasana belajar dan proses pembelajaran agar siswa secara aktif mengembangkan potensi dirinya untuk memiliki kekuatan spiritual keagamaan, pengendalian diri , kepribadian, kecerdasan, akhlak mulia serta keterampilan yang diperlukan dirinya, masyarakat, bangsa dan negara.

Pendidikan dikenal dengan pendidikan intrakulikuler, kokurikuler dan ekstrakulikuler. Pendidikan intrakulikuler pendidikan yang dilakukan guru untuk mendalami ilmu pengetahuan. Sedangkan korikuler kegiatan yang bertujuan mendalami pembelajaran dalam kegiatan intrakurikuler. Korikuler merupakan kegiatan yang dilakukan di luar jam sekolah dalam jurnal (Muliana, (2014:90). Sedangkan ekstrakulikuler pendidikan yang sebagai implementasi ilmu yang dipelajari sesuai dengan tuntutan kehidupan. "Kegiatan ekstrakulikuler merupakan kegiatan yang dilakukan diluar jam pelajaran seperti dokter kecil, PMR, pendidikan kepramukaan untuk mengembangkan bakat dan minat dalam mengembangkan karakter sikap manusia "( Mustaf, 2012: 230).

Sikap disiplin dapat di tanamkan melalui kegiatan ekstrakulikuler. Salah satu kegiatan yang sesuai dengan tuntutan saat ini adalah kegiatan pendidikan kepramukaan. Gerakan pendidikan kepramukaan ini juga menjadi ekstrakulikuler wajib yang dilaksanakan di setiap sekolah dalam mengimplementasikan kurikulum 2013.Kegiatan pendidikan kepramukaan menurut Undang-Undang Republik Indonesia Nomor 12 Tahun 2010 pasal 11 tentang gerakan Pramuka menyatakan bahwa pendidikan kepramukaan dalam sistem pendidikan Nasional termasuk dalam jalur pendidikan non formal yang diperkaya dengan pendidikan dengan nilai-nilai gerakan pramuka dalam pembentukan kepribadian yang berakhlak mulia, berjiwa 
patriotik, taat hukum, disiplin, menjunjung tinggi nilai-nilai luhur bangsa dan memiliki kecakapan hidup.

Sedangkan menurut Komalasari (2017: 135) ekstrakulikuler pramuka bertujuan untuk membentuk individu agar berpribadian yang beriman, berakhlak mulia, berjiwa patriotik, taat hukum, disiplin, menjunjung tinggi nilai-nilai luhur bangsa dan memiliki kecakapan hidup sebagai kader bangsa dalam menjaga dan membangun Negara Kesatuan Republik Indonesia, mengamalkan Pancasila, serta melestarikan lingkungan hidup.

Berdasarkan dari beberapa paparan di atas disimpulkan bahwa untuk dapat membentuk sikap disiplin siswa dapat dilakukan dengan kegiatan ekstrakulikuler pendidikan kepramukaan. Siswa dibiasakan untuk selalu menjaga ketakwaannya kepada Tuhan Yang Maha Esa, bertanggung jawab setiap apa yang dikerjakan, datang tepat waktu, selalu menjalankan segala pekerjaan sesuai dengan aturan yang berlaku

Berdasarkan permasalahan yang ditemukan peneliti selama perlu dilakukan sebuah penelitian upaya membuktikan apakah terdapat hubungan antara siswa yang aktif mengikuti kegiatan ekstrakulikuler kepramukaan dengan tingkat disiplin yang dimilikinya. Oleh sebab itu judul yang diangkat oleh peneliti dalam penelitian ini adalah "Hubungan antara Keaktifan Mengikuti Kegiatan Ekstrakulikuler Pendidikan Kepramukaan dengan Sikap Disiplin Siswa Kelas Tinggi Sekolah Dasar Negeri 36 Kota Bengkulu. Penelitian ini bertujuan untuk mengetahui hubungan antara siswa yang aktif mengikuti kegiatan ekstrakurikuler pendidikan kepramukaan dengan sikap disiplin yang milikinya.

\section{Metode}

Penelitian ini adalah penelitian kuantitatif .Metode penelitian korelasi dengan analisis data produck moment. Karakteristik desain penelitian ini adalah mencari hubungan antara dua variabel atau lebih, mencari besarnya hubungan yang didasarkan pada koofisien korelasi.

Populasi dalam penelitian ini adalah seluruh siswa yang mengikuti kegiatan ekstrakurikuler pendidikan kepramukaan yang berjumlah 57 .

Sampel merupakan sebuah bagian dari populasi. Dalam pengambilan sampel pada penelitian ini dilihat dari kriteria siswa yang dikatakan aktif dalam kegiatan pendidikan kepramukaan dengan skor kehadiran 2- 4 kali dalam sebulan dalam kegiatan kepramukaan Sehingga sampel pada penelitian ini seluruh jumlah populasi yaitu 57 siswa.

Instrumen pada penelitian ini menggunakan lembar angket(kuesioner). Teknik pengumpulan data menggunakan penyebaran lembar angket. Teknik analisis data menggunakan (1) uji normalitas dengan uji Chi Kuadrat $\left(X^{\wedge} 2\right)$, (2) uji homogenitas dengan $\mathrm{F}$ hitung, dan (3) uji hipotesis dengan menggunakan rumus korelasi Pearson product moment.

\section{Hasil}

Dari hasil penelitian terdiri dari variabel bebas (independen) keaktifan kegiatan ekstrakurikuler pendidikan kepramukaan dan variabel terikat (dependen) sikap disiplin. Pada bagian ini membahas deskripsi masing-masing variabel. Pertama disajikan tabel penolong (tabel frekuensi) untuk uji menentukan normalitas data. Yang kedua membandingkan data untuk menentukan uji homogenitas data dan yang terakhir pengujian hipotesis menggunakan dengan uji korelasi product moment. secara rinci data disajikan sebagai berikut :

a) Uji normalitas

Uji normalitas data menggunakan chi kuadrat $\mathrm{X}^{\wedge} 2$ ) dengan bantuan Microsoft Office Excel 2010. Diperoleh hasil uji normalitas sebagai berikut: 
Tabel 1 Hasil Uji Normalitas Data

\begin{tabular}{|c|c|c|c|c|}
\hline No & variabel & $X_{\text {hitung }}^{2}$ & $X_{\text {tabel }}^{2}$ & keterangan \\
\hline 1. & $\begin{array}{lr}\text { keaktifan } & \text { mengikuti } \\
\text { ekstrakurikuler } & \text { pendidikan } \\
\text { kepramukaan } & \end{array}$ & 11,46 & 14,067 & normal \\
\hline 2. & sikap disiplin siswa & 12,44 & 14,067 & normal \\
\hline
\end{tabular}

Berdasarkan tabel tersebut disimpulkan bahwa data keaktifan mengikuti kegiatan ekstrakurikuler pendidikan kepramukaan dan sikap disiplin bersifat normal pada signifikan 0,05 .

b) Uji Homogenitas

Uji homogenitas data menggunakan uji-F. Perhatiakan tabel hasil uji varian homogenitas data berikut ini

Tabel 2 Hasil Uji Varian Homogenitas Data

\begin{tabular}{clc}
\hline No & \multicolumn{1}{c}{ Variabel } & varian (s) \\
\hline 1. & $\begin{array}{l}\text { keaktifan mengikuti ekstrakurikuler pendidikan } \\
\text { kepramukaan }\end{array}$ & 14,54 \\
2. & sikap disiplin siswa & 8,57 \\
\hline
\end{tabular}

Berdasarkan data tersebut selanjutnya dilakukan Selanjutnya dilakukan perhitungan F_(hitung )dan diperoleh nilai $F_{-}$(hitung )= 1,70. Sedangkan F_(tabel )pada taraf signifikan $\alpha=0,05$ dengan pembilang u ntuk varian terbesar $\mathrm{n}-1=(57-1)=56$ dan penyebut untuk varian terkecil $\mathrm{n}-1=(57-1)=56$ adalah 1,90 . F_hitung $=1,70 \leq$ F_tabel=1,90 maka dapat disimpulkan bahwa data homogen.

\section{c) Uji hipotesis}

Hipotesis yang diajukan dalam penelitian ini adalah Ha yaitu terdapat hubungan antara keaktifan mengikuti ekstrakurikuler pendidikan kepramukaan dengan disiplin siswa kelas tinggi Sekolah Dasar 36 Kota Bengkulu. Berdasarkan hasil analisis data kedua variabel diperoleh $r$ _hitung $=0,66$ dan $r$ _tabel $=0,266$ dengan uji signifikan diperoleh t_hitung $=6,8$ dan t_tabel $=1,67303$.

Tabel 3 Rekapitulasi Uji hipotesis

\begin{tabular}{ccccc}
\hline No & & Variabel & nilai hitung & nilai tabel \\
\hline 1. & uji r & 0,66 & 0,266 \\
2. & uji t & 6,8 & 1,67303
\end{tabular}

Berdasakan tabel di atas dapat disimpulkan bahwa terdapa hubungan antara keaktifan mengikuti ekstrakurikuler pendidikan kepramukaan dengan sikap disiplin siswa dimana nilai $r_{\text {hitung }}=0,66 \geq 0,266$ yang artinya terdapat korelasi variabel X dan Y. Berdasarkan hasil uji hipotesis hubungan antara keaktifan mengikuti ekstrakurikuler pendidikan kepramukaan dengan sikap 
disiplin siswa diperoleh $r$ hitung $=0,66$ maka $K P=r^{\wedge} 2 \times 100 \%=\llbracket 0,66 \rrbracket^{\wedge} 2 \times 100$ $\%=43,56 \%$. Hasil perhitungan diperoleh nilai t_hitung=6,8 dengan $\mathrm{dk}=\mathrm{n}-2=57-2$ $=55$ dan $\alpha=0,05$ sebesar $=1,67303$ dengan $\mathrm{t} \_$hitung $=6,8 \geq \mathrm{t} \_$tabel $=1,67303$, maka H_(O )ditolak dan H_a diterima. Jadi dapat disimpulkan bahwa terdapat hubungan antara keaktifan mengikuti ekstrakurikuler pendidikan kepramukaan.

\section{Pembahasan}

Penelitian ini dapat memberikan gambaran dari masalah yang telah diangkat. Pengujian hipotesis dilakukan pembekuan instrumen penelitian dengan melakukan validitas instrumen angket dan reliabilitas instrumen penelitian. Dari validitas angket keaktifan mengikuti ekstrakurikuler pendidikan kepramukaan dari 25 pernyataan hanya 21 yang valid serta reliabel dan 4 pernyataan tidak valid. Sedangkan angket sikap disiplin dari 20 pernyataan hanya 17 yang valid serta reliabel dan 3 yang tidak valid.

Berdasarkan pengujian hipotesis peneliti terlebih dahulu uji prasayarat untuk memenuhi analisis hipotesis yaitu uji normalitas dan homogenitas. Uji homogenitas menggunakan rumus Chi Kuadrat ( $\left.\mathrm{X}^{\wedge} 2\right)$. Diperoleh hasil uji normalitas data variabel keaktifan mengikuti kegiatan ekstrakurikuler pendidikan kepramukaan dengan $\left.\llbracket \mathrm{x}^{\wedge} 2 \rrbracket\right]$ hitung $=11,46 \leq \llbracket \mathrm{x}^{\wedge} 2 \rrbracket$ tabel=14,067 artinya variabel keaktifan mengikuti kegiatan ekstrakurikuler pendidikan kepramukaan berdistribusi normal. Diperoleh hasil uji normalitas data variabel sikap disiplin siswa dengan $\llbracket \mathrm{x}^{\wedge} 2 \rrbracket \_$hitung $=12,44 \leq \llbracket \mathrm{x}^{\wedge} 2 \rrbracket \_$tabel=14,067 artinya semua data berdistribusi normal.

Pengujian homogenitas menggunakan uji F dengan bantuan Microsoft Office Excel 2010. Uji homogenitas variabel keaktifan mengikuti kegiatan ekstrakurikulr pendidikan kepramukaan memperoleh nilai varian (s) 14,54 sedangkan sikap disiplin siswa memperoleh 8,57. Selanjutnya dilakukan perhitungan 『F 》_hitung dengan hasilnya 1,26. Sedangkan 『F \_tabel adalah 1,90. 『F \_hitung $=1,70 \leq \llbracket F$ 』_tabel $=1,90$ artinya data homogen.

Berdasarkan pengujian hipotesis peneliti menggunakan rumus product moment menggunakan bantuan Microsoft Office Excel 2010. Hasil penelitian diketahui bahwa nilai $r_{-}$hitung $=0,66 \geq r_{-}$tabel0,266. Hasil perhitungan menunjukan bahwa antara keaktifan mengikuti ekstrakurikuler pendidikan kepramukaan dengan sikap disiplin siswa memiliki hubungan yang kuat berada pada rentang 0,60 - 0,799 yang dilihat pada tabel interpretasi nilai $\mathrm{r}$ Sugiono (2012:142). Kegiatan ini menjadikan tempat untuk menumbuhkan sikap disiplin. Dari setiap kegiatan yang dilakukan dalam pendidikan kepramukaan seperti pada saat baris berbaris siswa diajarkan untuk memiliki sikap disiplin, tanggung jawab, ketekunan, kerjasama. Sesuai dalam jurnal Pratiwi( 2020 : 65-66) Ekstrakurikuler pramuka memiliki peranan yang penting dalam menumbuhkan disiplin siswa dikarenakan kegiatan ekstrakurikuler pramuka dianggap kegiatan yang menarik bagi siswa sehingga melalui kegiatan ekstrakurikuler pramuka siswa dapat mudah dilatih dan dibiasakan untuk disiplin dengan mematuhi tata tertib yang telah ditetapkan.

Selain kegiatan baris berbaris ada juga kegiatan tali temali yang dapat dapat menumbuhkan sikap disiplin siswa. Seperti pada saat mereka melakukan kegiatan tersebut siswa harus saling bekerja sama dan disiplin. Namun, pada setiap kegiatan memiliki kendala misalnya siswa sering berebut alat yang akan mereka gunakan. Saat itulah anak harus dilatih memiliki sikap disiplin dalam menggunakan waktu. Apabila waktu yang telah ditetapkan pembina untuk menyelesaikan masalah setiap kelompok maka setiap kelompoknya harus tepat waktu dalam menyelesaikan tugas tersebut, karena jika siswa tidak tepat waktu maka kelompok yang lainnya tidak dapat menggunakan fasilitas yang disedikan oleh pembina pramuka. Sehingga dari kegiatan pendidikan kepramukaan siswa 
memiliki banyak nilai yang dapat oleh siswa. Sesuai jurnal Rahman dan Angrianti ( 2020:22) bahwa ekstrakurikuler pramuka memiliki hubungan yang signifikan terhadap disiplin siswa untuk seluruh siswa di SMA Negeri 8 Kota Serang. Hal itu terlihat ketika siswa mengikuti ekstrakurikuler pramuka yang didalamnya mempunyai banyak nilai-nilai dan manfaat bagi siswa agar tumbuh sikap disiplin.

Selain itu sikap disiplin juga dapat ditumbuhkan pada saat upacara pembukaan. Siswa dilatih untuk disiplin waktu mereka harus mengikuti upacara pembukaan dalam pendidikan kepramukaan dengan tepat waktu dan dalam menggunakan atribut pramuka dengan lengkap. Selain itu juga siswa dalam kegiatan tidak boleh main-main dalam setiap kegiatan.

Kegiatan ekstrakurikuler ini tidak hanya dilakukan di sekolah saja. Karena jika hanya dilakukan disekolah banyak siswa yang merasa malas dalam mengikuti kegiatan kepramukaan apabila kegiatan yang dilakukan pembina pramuka tidak menarik bahkan mereka banyak yang tidak hadir dalam kegiatan. Tetapi, jika dilakukan di luar sekolah siswa merasa senang dan bersemangat bahkan siswa yang jarang hadir dalam kegiatan akan datang untuk mengikuti kegiatan tersebut. Misalnya siswa di bawa ke taman atau pun kepantai agar tidak menumbuhkan rasa bosan siswa di sekolah. Kegiatan di luar sekolah siswa juga di tumbuhkan sikap disiplin misalnya siswa tidak boleh merusak fasilitas-fasilitas di lingkungan dimana siswa melakukan kegiatan kepramukaan. Karena dalam kegiatan tersebut dapat menumbuhkan semangat siswa dalam setiap kegiatan karena anak lebih mudah memahami dan sangat menyenangkan dalam proses kegiatan kepramukaan karena di dalam pendidikan kepramukaan terdapat unsur bermain dalam belajar sehingga anak merasa tidak tertekan. Sesuai dengan hasil perhitungan sumbangan konstribusi variabel keaktifan mengikuti ekstrakurikuler pendidikan kepramukaan (X) terhadap variabel sikap disiplin siswa (Y) yaitu 43,56 \%. Sisa lebih dari 50\% tidak disumbangkan dari keaktifan mengikuti ekstrakurikuler pendidikan kepramukaan. Dari hasil tersebut seharusnya guru atau pembina pramuka dapat meningkatkan minat dari siswa untuk mengikuti kegiatan kepramukaan sehingga siswa dapat ditumbuhkan berbagai karakter dalam diri siswa salah satunya sikap disiplin.

Karena sikap disiplin sangat penting dimiliki siswa saat ini sikap disiplin siswa menurun sehingga untuk menumbuhkan sikap disiplin dapat dilakukan dengan pendidikan kepramukaan. Dari pendapat di atas maka keaktifan mengikuti ekstrakurikuler pendidikan kepramukaan memiliki hubungan dengan sikap disiplin siswa. Hal ini sesuai dalam jurnal Elisa dkk ( 2019 : 116) kegiatan ekstrakurikuler pramuka ini mengarahkan anak didiknya untuk mengembangkan sikap yang sesuai kehidupan bangsa dan negara.Sesuai dengan tujuan Gerakan Pramuka dalam Undang-undang Republik Indonesia Nomor 12 Tahun 2010 Pasal 4 tentang gerakan pramuka yang menyatakan bahwa kegiatan ekstrakurikuler pendidikan kepramukaan dilakukan untuk membentuk setiap anggota pramuka agar memiliki kepribadian yang beriman, bertakwa, berakhlak mulia, berjiwa patriotik, taat hukum, disiplin, menjunjung nilai-nilai luhur bangsa, dan memiliki kecakapan hidup sebagai kader bangsa dalam menjaga dan membangun Negara Kesatuan Republik Indonesia, mengamalkan pancasila, serta melestarikan lingkungan hidup. Kegiatan ekstrakulikuler merupakan kegiatan yang dilakukan diluar jam pelajaran seperti dokter kecil, PMR, pendidikan kepramukaan untuk mengembangkan bakat dan minat dalam mengembangkan karakter sikap manusia "( Mustaf, 2012: 230).

Salah satu tujuan kegiatan ekstrakurikuler pendidikan kepramukaan adalah untuk membentuk siswa memiliki sikap disiplin. Sehingga siswa yang ikut dalam kegiatan ekstrakurikuler pendidikan kepramukaan akan dibina untuk memiliki sikap yang disiplin dan berakhlak baik dalam lingkungan sekolah atau luar sekolah. Selain itu Dari penelitian ini terlihat ada hubungan antara keaktifan mengikuti ekstrakurikuler pendidikan kepramukaan dapat membentuk sikap disiplin sehingga dalam kurikulum 2013 ekstrakurikuler kepramukaaan menjadi 
ekstrakurikuler wajib. Sesuai dalam jurnal Damanik ( 2014: 21) Pramuka menjadi ekstrakulikuler wajib disekolah sangatlah penting bagi para peserta didik, agar peserta mendapatkan bekal ilmu, keterampilan,kedisiplinan, bertaqwa dan berkarakter.

Hasil perhitungan sumbangan konstribusi variabel keaktifan mengikuti ekstrakurikuler pendidikan kepramukaan (X) terhadap variabel sikap disiplin siswa (Y) yaitu 43,56 \%. Dapat disimpulkan sedikit sumbangan dari konstribusi variabel keaktifan mengikuti ekstrakurikuler pendidikan kepramukaan (X) terhadap variabel sikap disiplin yaitu 43,56 \%.Sehingga diharapkan siswa yang memiliki keaktifan kepramukaan dapat memiliki sikap yang dapat diterapkan di sekolah ataupun diluar sekolah.

\section{Simpulan}

Dari hasil penelitian dan pembahasan disimpulkan bahwa dari perhitungan korelasi r_hitung >r_tabel disimpulkan bahwa terdapat hubungan antara keaktifan mengikuti ekstrakurikuler pendidikan kepramukaan dengan sikap disiplin. Hal tersebut dapat dilihat dari hasil perhitungan antara $r$ _hitung $=0,66 \geq r_{-}$tabel0,266 pada taraf signifikan $5 \%$ dan $\alpha=0,05$ sehingga masuk dalam taraf hubungan yang kuat. Dari hasil presentase terhadap nilai $\mathrm{r}$ diperoleh sumbangan keaktifan mengikuti ekstrakurikuler pendidikan kepramukaan dengan sikap disiplin kelas tinggi Sekolah Dasar Negeri 36 Kota Bengkulu sebesar 43,56 \%.

\section{Saran}

Berdasarkan hasil penelitian yang telah dilakukan, peneliti mengemukakan Berdasarkan hasil penelitian yang dilakukan, maka peneliti mengemukakan beberapa saran sebagai berikut:

1. Bagi guru

Berdasarkan hasil penelitian bahwa terdapat hubungan yang kuat anatara keaktifan mengikuti kegiatan ekstrakurikuler pendidikan kepramukaan dengan sikap disiplin siswa. Siswa yang kurang aktif dalam kegiatan pendidikan kepramukaan memiliki sikap disiplin yang rendah. Maka untuk itu, peneliti menyarankan bagi guru memotivasi siswa yang kurang aktif untuk meningkatkan keaktifannya dalam mengikuti kegiatan ekstrakurikuler pendidikan kepramukaan. Selain itu guru juga dapat memberikan kegiatan yang menarik bagi siswa sehingga siswa dapat tertarik untuk mengikuti kegiatan ekstrakurikuler pendidikan kepramukaan serta fasilitas yang diberikan sehingga siswa tidak berebut dalam menggunakan peralatan pada saat kegiatan.

2. Bagi Peneliti Selanjutnya

Penelitian ini dapat digunakan pada peneliti selanjutnya dengan permasalahan yang sama namun dikaitkan dengan sikap lainnya yang terdiri dari sikap jujur, toleransi, kerjasama,kreatif, mandiri, demokratis, rasa ingin tau, semangat kebangsaan, cinta tanah air, tanggung jawab, cinta damai dan lainnya.

\section{Referensi}

Aini, Sri Nur. (2015). Kedisiplinan Siswa, Motivasi Belajar dan Peningkatan Prestasi Belajar PPKn Siswa. Jurnal Penlitian dan Pendidikan IPS. Jilid 7, Nomor 10, file:///Users/Hp/Downloads/703-749-2PB\%20(1).pdf, diakses 20 Desember 2016

Damanik, Saipul Ambri.(2014). Pramuka Ekstrakurikuler Wajib Di Sekolah. Jurnal

Ilmu Keolahragaan. Volume 13, Nomor 2,
https://jurnal.unimed.ac.id/2012/index.php/JIK/article/view/6090, diakses desember 2014

Elisa, dkk. (2019). Penanaman Nilai-Nilai Pendidikan Karakter Siswa Melalui Kegiatan Ekstrakulikuler Pramuka. Mimbar PGSD Undiksh. Volume 7, 
nomor 2, file://C:/Users/ACER/Downloads/17553-25302-1-SM\%20(1).pdf ， diakses 2019

Elly, Rosma.(2016) Hubungan Kedisiplinan Terhadap Hasil Belajar Siswa Kelas V Di Sd Negeri 10 Banda Aceh. Pesona Dasar. Volume 3, Nomor 4, file://C:/Users/ACER/Downloads/7540-16495-1-SM\%20(1).pdf, diakses pada oktober 2016

Fathurrohman, Pupuh., et al. 2013. Pengembangan Pendidikan Karakter. Bandung : PT Refika Aditama

Komalasari, Kokom dan Didin. (2017). Pendidikan Karakter. Bandung : PT Refika Aditama

Muliana, Raudati. (2014) Penerapan Pendidikan Karakter Di Sdn 06 Pangkalan Kecamatan Koto Baru Kabupaten Lima Puluh Provinsi Sumatera Barat. Jurnal Ilmu-ilmu Sejarah, Budaya dan Sosial. https://www.neliti.com/id/publications/22987/penerapan-pendidikan-karakterdi-sdn-06-pangkalan-kecamatan-koto-baru-kabupatenDiakses pada 2014

Mustaf, Jejen. (2012). Pendidikan Holistik. Jakarta : KENCANA PRENADA MEDIA GROUP

Pratiwi, Septian Intan. (2020) Pengaruh ekstrakurikuler pramuka terhadap karakter disiplin siswa SD. Jurnal Ilmu Pendidikan. Voume 2, nomor 1, https://edukatif.org/index.php/edukatif/article/view/90 . diakses april 2020

Rahman, dan Anggrianti .(2020) Pengaruh Ekstrakurikuler Pramuka Terhadap Disiplin Siswa (Study Expost Facto). Jurnal Pelita Bumi Pratiwi. Volume 04, nomor

http://jurnal.stkippelitapratama.ac.id/index.php/pertiwi/article/view/28, diakses 2020

Republika Indonesia. 2003. Undang- undang No 20 tahun 2003 Tentang Sistem Pendidikan Nasional. Sekertariat Negara : Jakarta. Diakses pada tanggal 22 November 2016. http:/hukum.unsrat.ac.id/uu/uu 20 03. Htm

Sugiyono. (2012). Metode Penelitian Kombinasi. Bandung : ALFABETA

Winarni, Endang Widi. (2018). Penelitian Kuantitatif Kualitatif. Jakarta : Bumi Aksara

Winarni, Endang Widi. (2011). Penelitian Pendidikan. Bengkulu : Unit Penerbitan FKIP UNIB 